\title{
Teamwork orientation and personal learning: The role of individual cultural values and value congruence
}

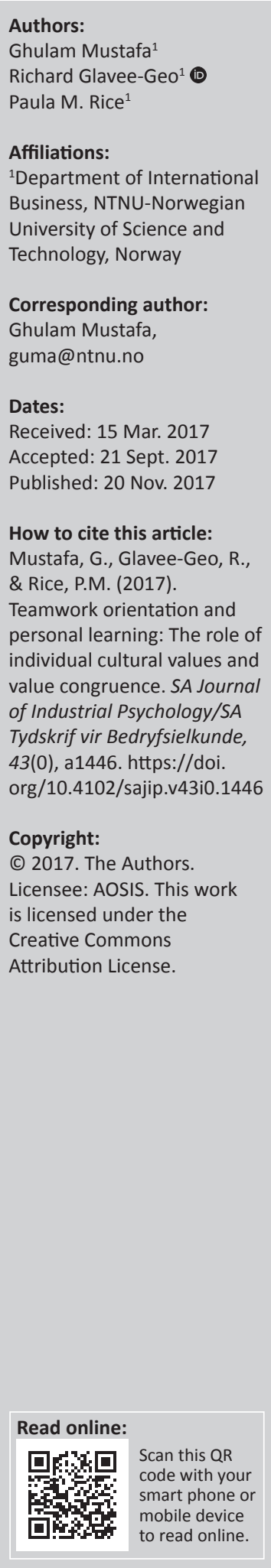

Orientation: There is a growing body of research that indicates that personal factors such as collectivist value orientation play an important role in individuals' preference for teamwork, and an individual's propensity to work in a team is seen as a contributing factor in one's personal learning.

Research purpose: The purpose of this article is twofold. Firstly, the article aims to explore whether individual-level cultural values of power distance, uncertainty avoidance and masculinity-femininity interact with individual collectivist values to influence teamwork orientation. Secondly, the study aims to examine the influence of teamwork orientation on personal learning further exploring the role of perceived value congruence in this relationship.

Motivation for the study: While an extensive amount of research has been conducted on teamwork orientation, the question of how individual cultural values influence formation of teamwork orientation is still largely unanswered. This lack is especially evident with regard to how the influence of collectivism on the development of positive attitudes towards teamwork is promoted or inhibited by other values such as power distance, uncertainty avoidance and masculinity-femininity. Moreover, the current evidence about the influence of teamwork orientation on personal learning and the role of personal and contextual factors in such a relationship is still scarce.

Research design, approach and method: The study used a cross-sectional survey, with data collected from 120 business students engaged in project teams at a Norwegian university. All the hypothesised relationships were assessed using partial least square structural equation modelling technique.

Main findings: The findings indicate that the link between collectivism-teamwork orientation is stronger for team members who scored high on uncertainty avoidance values and the relationship was weaker for team members who endorsed high-power distance values. Teamwork orientation was significantly associated with personal learning independent of the degree of perceived value congruence between individual member and other team members.

Practical or managerial implications: Our study offers implications for managing teams and facilitating employee learning and development in organisations. The study may also benefit teachers in higher education in facilitating students' learning through group activities.

Contribution or value-added: This study provides initial evidence on the contingent effect of power distance and uncertainty avoidance in the collectivism-teamwork orientation relationship. The study further contributes to the existing literature on the effects of preference to work in teams by assessing the influence of teamwork orientation on personal learning in addition to considering the role of perceived value congruence in this relationship.

\section{Introduction}

Teamwork orientation, defined as the extent to which members have a positive attitude towards working in a team (Fransen, Kirschner \& Erkens, 2011; Mathieu, Maynard, Rapp \& Gilson, 2008), is an essential aspect of teamwork (Salas, Sims \& Burke, 2005). Such an attitude reflects the level of an individual's willingness to work with others in a cooperative manner, and his or her commitment to group goals and interpersonal relationships (Watson, Johnson \& Merritt, 1998). Team orientation has been found to improve individual effort and performance within a team (Mohammed \& Angell, 2004; Shamir, 1990; Wagner, 1995), team member exchange (Wang, Li, Wu \& Liu, 2014) propensity to participate in the team work and cooperate with other team 
members (Eby \& Dobbins, 1997), individual satisfaction (Campion, Medsker \& Higgs, 1993) and personal learning (Williams, Duray \& Reddy, 2006).

The discussion of the factors that influence the extent to which individuals are team-oriented has identified collectivist values as an important factor increasing an individual's propensity to cooperate in team settings (Earley \& Gibson, 1998; Wagner, 1995). Although there is extensive research on collectivism at the cultural level (Hofstede, 2001; Van Hoorn, 2015), more recently researchers have begun to study collectivism as an individual difference variable in team contexts (Dierdorff, Bell \& Belohlav, 2011; Jackson, Colquitt, Wesson \& Zapata-Phelan, 2006; Mayfield, Tombaugh \& Lee, 2016). Given that collectivism represents the degree to which an individual values interdependence and attaches importance to group over individual goals (Triandis, 1995; Wagner, 1995), it seems logical to examine its influence on the development of positive attitudes towards teamwork. The existing research, however, has investigated the role of collectivism on team-oriented attitudes and behaviours in isolation, neglecting the role of other values in these relationships. The researchers are not aware of any past studies that have examined the role of other values such as power distance (PD), uncertainty avoidance (UA) and masculinity-femininity in complementing or inhibiting the influence of members' individually held collectivist values on team-oriented attitudes and behaviours. Schwartz (1992) and Schwartz and Butenko (2014) underscore that a complete value profile should be considered rather than analysing values in isolation when examining how values relate to attitudes and behaviours. Likewise, Kirkman, Lowe and Gibson (2006) argue that there are no theoretical rationales for surmising that cultural values influence outcomes independent of each other, and these authors call for an examination of the interaction effects of cultural values.

Many recent and past studies have examined the consequences of teamwork orientation for individual- and group-level outcomes (Bell, 2007; Driskell \& Salas, 1992; Mohammed \& Angell, 2004; Rahman, Rehman, Imran \& Aslam, in press; Singh, Chaudhry, Vidyarthi \& Posthuma, 2014). Among these, a few researchers have also reported an association between preference to work in team settings and personal learning (Williams \& Castro, 2010; Williams et al., 2006). However, the current evidence that supports the influence of teamwork orientation on personal learning is still too limited to corroborate such a relationship. Moreover, the existing research has yet to enrich our understanding of the dynamic interplay between team orientation and personal and contextual factors in predicting outcomes. This lack is particularly evident in establishing whether congruity of one's deep-level value orientations influences this relationship. There are, however, a few exceptions. For example, Eby and Dobbins (1997) suggested that certain individual difference variables such as self-efficacy and locus of control may influence team orientation and performance relationship, while Williams and Castro (2010) in their recent study reported that the influence of team orientation on personal learning tends to depend on the team environment. This study therefore seeks to investigate (1) whether individual-level cultural values of PD, UA and masculinityfemininity interact with individual collectivist values to influence teamwork orientation, and (2) whether there is a significant relationship between teamwork orientation and personal learning and whether perceived value congruence plays a role in this relationship.

\section{Research purpose}

As noted earlier, an extensive amount of research has been conducted on teamwork orientation, but the question of how individual cultural values influence the formation of teamwork orientation, is still largely unanswered. This lack is especially evident with regard to how the influence of collectivism on the development of positive attitudes towards teamwork is promoted or inhibited by other values such as PD, UA and masculinity-femininity. Moreover, the current evidence regarding the influence of teamwork orientation on personal learning and the role of personal factors in such a relationship, is still scarce. The purpose of this study is to fill these gaps in the existing literature by exploring the role of PD, UA, and masculinity-femininity in the relationships between collectivism and teamwork orientation. Our focus on cultural values is at the individual level of analysis and this approach of treating cultural values as psychological constructs is consistent with research in applied psychology and management (Kirkman, Chen, Farh, Chen \& Lowe, 2009) and research in higher education (Yoo \& Donthu, 2002). The study further aims to extend previous research by examining the influence of teamwork orientation on personal learning in addition to assessing the degree to which the effects of team orientation on personal learning vary as a function of one's perceived similarity of his or her values with that of other members of the team. The constructs and relationships tested in the study are illustrated in Figure 1.

\section{Literature review and hypotheses Individual-level cultural values as predictors of attitudes}

There is a lack of consensus among scholars as to whether values are properties of the person or that of the collective. Those who subscribe to a psychological perspective argue that values are properties of individuals. According to Schwartz (1992), values are abstract beliefs about desirable goals, ordered in a system of priority, that guide an individual's evaluation of events, actions and people. This

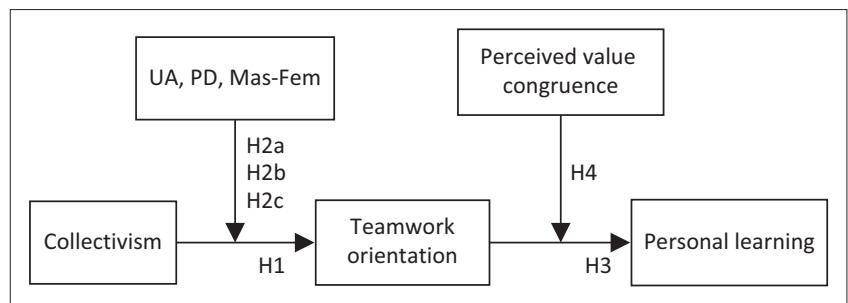

FIGURE 1: Conceptual model. 
view holds that there is extensive variability of values across individuals within the same country. The culture-comparative perspective assumes that values are shared meaning systems (Hofstede, 2001; Minkov \& Hofstede, 2012) that distinguish one cultural group (country) from the other. According to this view, there is generally a high level of consensus on a set of values within cultural groups, while there are relatively large differences between groups. A sociological view suggests that social institutions and other macro-level factors affect the modal importance of individuals' values within societies, but people differ in the extent to which they internalise these modal values (Fischer \& Schwartz, 2011). There is ample evidence in earlier empirical studies that variation in value ratings between individuals is higher than between countries. For example, Fischer and Schwartz's (2011) study contends that most values that many researchers consider constitute societal culture are not part of the shared meaning systems. According to them, within-country consensus is relatively low for most values, and inter-country differences do not account for considerable variance.

In view of the intra-cultural variations in values, several researchers have underscored the importance of examining cultural variables at the individual level (e.g. Ralston et al., 2014; Sharma, 2010) as manifested in how strongly an individual adheres to different cultural value dimensions (Patterson, Cowley \& Prasongsukarn, 2006; Triandis, 1995). According to Triandis (1995), there is an individual analogue for the macro-level cultural dimensions, which suggests that cultural syndromes evident at societal level may also manifest themselves at the individual level. Researchers who support an individual-level approach to the assessment of cultural values argue that within-country variation that inevitably exists in every society cannot be captured by utilising only a country-level approach (Ralston et al., 2009). To test empirical predictions at an individual level, several subsequent studies have adopted Hofstede's (1980) cultural dimensions (Kirkman et al., 2009; Mustafa \& Lines, 2014) using individuallevel measures, such as those developed by Dorfman and Howell (1988) and Yoo, Donthu and Lenartowicz (2011).

Although values are abstract concepts, there is sufficient empirical support to show that individuals' attitudes, decision-making processes and behaviours are influenced by their values (Bardi \& Schwartz, 2003). Previous research has also shown that individually held values influence a variety of individuals' attitudes and behaviours at work (Gelfand, Erez \& Aycan, 2007; Tsui, Nifadkar \& Ou, 2007). It has been argued that despite the importance of societal culture in shaping individuals' values, there are inherent individuallevel differences that may cause employees to use different frames of reference when they interpret and make sense of their work environments, resulting in differences in work attitudes (Alper, 1975; Slocum \& Strawser, 1972). In their meta-analytic study, Taras, Kirkman and Steel (2010) found that individual cultural values showed a stronger relationship to attitudes and perceptions than to behaviours. Cultural values showed better predictive validity with respect to attitudes than demographics, general mental ability and personality. Given the earlier evidence that cultural values are more proximally related to attitudes than other individual difference variables such as personality (Taras et al., 2010), it seems logical to examine the influence of collectivist values on teamwork orientation while controlling for the effects of other individual-level values. Teamwork orientation is essentially attitudinal (Fransen et al., 2011) because it indicates an individual's preference for a certain work environment, while values such as collectivism are general beliefs that transcend specific situations. Thus, individual values should impact even stable attitudes such as team orientation, because values are more ingrained and more general than other dispositional attributes (England \& Lee, 1974).

\section{Collectivism and teamwork orientation}

Individuals who are assigned to perform work in teams often begin to work closely with a group of new team members (Manz \& Sims, 1993). The group welfare tends to take precedence over the individual welfare as a sense of cohesion and interdependence is built within the team (Hackman, 1987). Teams characterised by high degree of task interdependence are composed of members who interact closely with each other and share information and other resources on a constant basis to accomplish team tasks (Kirkman \& Shapiro, 1997). The willingness and ability of team members to work together in a truly cooperative manner concerning the achievement of shared goals is referred to as teamwork orientation (Lick, 2000). It reflects the extent to which a member has a positive attitude towards working in team-based settings (Mathieu et al., 2008) such as eagerness to combine efforts with others, showing empathy and responsiveness in interpersonal relations and showing commitment to collective goals (Watson et al., 1998). Thus, an employee's willingness to work interdependently rather than in an independent manner may correspond to his or her collectivist orientation.

Collectivism reflects a preference for a social and workplace framework in which people expect cooperation, collaboration and mutual interdependence from others in their groups (Shamir, 1990). Individuals with a high collectivist orientation tend to focus on shared objectives and cooperation (Walumbwa, Lawler \& Avolio, 2007), member collectivist orientation is important for developing work teams that are cooperative and productive (Eby \& Dobbins, 1997). In contrast, individualist values reflect a strong emphasis on the achievement of individualised goals and the importance of individual roles within the work group or the organisation (Triandis, 2006). At the workplace, individuals with a low collectivist orientation may be resistant to teamwork; they are likely to show lower trust in co-workers and maybe less committed to team members (Kirkman \& Shapiro, 1997). Thus, it seems probable that individuals characterised by collectivist values will have more of the attitudes that result in readiness to work in team contexts, emphasise mutual interdependence and advocate group goals and interests. Based on the above, we propose the following: 
H1: Collectivism is positively related to individual teamwork orientation.

\section{Interactive effects of collectivism and other values}

The value theory posits that any attitude or behaviour is a product of trade-offs between the values that promote and oppose it (Schwartz, 1992). Values are argued to be compatible if attitudes and behaviours that express the goals of one also promote the goals of the other and they conflict if the outcomes that express the goals of one do so at the expense of the other. Apart from rare exceptions such as Feldman, Chao, Farh and Bardi (2015), past research on the effects of values on individual outcomes such as attitudes and behaviours has mainly focused on how a value promotes or inhibits certain outcomes (Bardi \& Schwartz, 2003; Schwartz \& Butenko, 2014), neglecting the roles other values may play in these relationships. Kirkman et al. (2006) argue that cultural values may not operate independently, rather they may interact with each other to influence outcomes. According to them, examining such interactions might provide insights into the complex relationships among different values. In the current study, we first theoretically surmise that the effects of collectivism on teamwork orientation will be accentuated when individual team members endorse high UA, low PD and feminine values compared to when members endorse low UA, high PD and masculine values. We then test our propositions empirically.

\section{Interaction of uncertainty avoidance and collectivism}

Uncertainty avoidance refers to the extent to which people seek orderliness, consistency, structure and clearly articulated expectations (Javidan \& House, 2001). High UA is associated with a desire to reduce ambiguity and a need for predictability, whereas low UA is associated with a propensity to engage in novel and risk-taking behaviour (Triandis, 1995). Applied to the work context, these dynamics may influence an individual's preference for work structures and processes that reduce or do not increase the level of uncertainty or support openness in thought and action. High UA values may enhance one's motivation to work in a social environment such as in a team, because work teams focus on setting goals, scheduling time and asserting effort towards timely completion of tasks that often have fixed deadlines. There are some studies that suggest that UA values tend to foster prosocial attitudes and behaviours. For example, in their metaanalysis, Taras et al. (2010) found that UA was positively associated with team commitment and cooperation in groups. Mustafa (2015) argues that an interdependent orientation would be more desirable for individuals who endorse high UA values. Furthermore, conservation values that are conceptually related to UA values have been reported to inhibit antisocial behaviour (Schwartz, 2007, 2010).

On the other hand, greater emphasis on openness in thought and action by individuals low on UA orientation may lead to reduced interdependence and cooperation by such individuals in group settings (e.g. Schwartz, 1992). Moreover, it has been noted that individuals who espouse low UA values tend to form short-term and multiple commitments (Chew \& Putti, 1995) that may inhibit the development of stable pro-social attitudes such as teamwork orientation. The study by Jackson (2001) provides partial support for this notion, contending that individuals from societies high on UA and collectivist values show more commitment to their work group compared to those from societies characterised by low UA and individualist values.

The above suggests that the effects of collectivism on teamwork orientation will be more pronounced when individuals are high rather than low on UA values. Therefore, our hypothesis is:

H2a: Collectivism-teamwork orientation relationship is stronger when members endorse high rather than low UA values.

\section{Interaction of power distance and collectivism}

Power distance refers to the degree to which individuals accept or even expect hierarchical differences in social relationships (Hofstede, 1980; Javidan, Dorfman, De Luque \& House, 2006; Smith, Peterson \& Schwartz, 2002). We argue that individuals who accept PD in interpersonal interactions will prefer those work environments that allow them to maintain PD, while those who expect low hierarchical differences will prefer work environments that reduce PD. With regard to one's inclination to work in teams, we suggest that teamwork may be less suitable to maintaining PD between members. A number of studies refer to the relevance of PD in team processes (e.g. Bouncken, Brem \& Kraus, 2016). According to Jaeger (1986), high PD renders team building a less efficacious management initiative, because high PD team members have a lower tendency to be involved in sharing information and knowledge, which leads to lower degree of communication in the team (Bouncken et al., 2016). On the other hand, low emphasis on PD improves the quality of communication in team settings (Chen \& Bliese, 2002; Zhang \& Begley, 2011). Individuals low on PD prefer high participation in decision-making, and show increased eagerness to share their ideas and opinions (Elenkov, 1998). It has been argued that cooperation and mutual support form the basis of relationships among people low on hierarchical values (Clugston, Howell \& Dorfman, 2000; Sagiv \& Schwartz, 2007), which, in turn, may promote work interdependence in team contexts.

The above discussion suggests that individuals with high collectivist orientation will show a high degree of teamwork orientation when they endorse low PD values. Consequently, we propose the following:

H2b: Collectivism-teamwork orientation relationship is stronger when members endorse low rather than high PD values.

\section{Interaction of masculinity-femininity and collectivism}

The masculinity-femininity orientation reflects the degree to which individuals value assertiveness, success and ambition as opposed to compassion, modesty and empathy (Hofstede, 2001). Within a work context, we expect a preference for 
those work activities that better cater to these values. For example, we expect masculinity to be less associated with a preference for working in a team setting. One of the reasons may be that a success-oriented drive may render individuals high on masculinity to adopt a self-centred approach and direct their efforts towards personal accomplishment over mutual goal attainment. Mustafa (2015) argues that individuals high on masculinity are less likely to see themselves as part of encompassing social relationships and their self-representation will be reflected by less inclusion of others. This is supported by Taras et al.'s (2010) study that suggests that masculinity inhibits cooperation in groups. Contrarily, individuals high on feminine values tend to be agreeable, cooperative and friendly in interpersonal interactions (Hofstede, 1980) and they focus on cultivating socio-emotional ties among members and building team cohesion (Cheng, Chua, Morris \& Lee, 2012). Thus, they may see themselves integrated with others in different social settings and may adopt a group's perspective. Past research offers several clues to augment the notion that femininity will be linked to perceptions of interdependent self-construal. For example, Cross and Madson (1997) suggest that women are more likely than men to construe themselves in an interdependent manner. Likewise, Schwartz and Rubel (2005) found that men value self-direction, while women value benevolence, which means that men are likely to pursue their preferences regardless of their relationships, while relationships and connections with others take priority for women over their personal interests.

The above suggests that a feminine orientation is likely to be more congruent with the characteristics of collectivist values, and thus the influence of collectivism on teamwork orientation will be amplified when one espouses feminine rather than masculine values. We therefore propose the following hypothesis:

H2c: Collectivism-teamwork orientation relationship is stronger when members endorse feminine rather than masculine values.

\section{Teamwork orientation and personal learning}

Teamwork orientation has been found to improve many individual outcomes such as willingness to cooperate with other team members (Eby \& Dobbins, 1997) and effort and performance within a team (Shamir, 1990; Wagner, 1995). Teamwork orientation has also been found to facilitate personal learning (Williams et al., 2006) which, as argued by Kram (1996), is the acquisition of knowledge, skills or competencies that contribute to personal development. Such acquisition may be effected through investing effort in teamrelated tasks (Costa, Passos \& Bakker, 2014), exchanging information and other materials as well as providing and seeking performance feedback (Mohammed \& Angell, 2004). For example, Driskell and Salas (1992) noted that teamoriented individuals more frequently sought their teammates' input when deciding on a final course of action. It has been argued that being receptive to feedback and assistance from other team members maybe valuable for work processes (Salas et al., 2005) resulting in a learning experience.
Many past studies suggest that team-oriented attitudes and skills such as effective collaboration in project work, interactions with other members and working cooperatively towards team goals may result in personal learning. It has been argued that individuals with a teamwork orientation perceive interaction and working actively with other teammates as useful for learning (Abrami \& Bures, 1996), and the knowledge acquired through interaction in a team environment facilitates overall personal learning (Williams et al., 2006). Individuals who appreciate being part of a team are less likely to withhold effort (Kidwell \& Bennett, 1993) and tend to act in ways that contribute to group functioning (Bell, 2007; Mohammed \& Angell, 2004). The extent to which team members show commitment to group goals and keenness to build team processes is portrayed in high levels of cooperation, a sense of cohesion and social support that have been reported to promote personal learning (Alavi, 1994). As argued by Williams and Castro (2010), positive attitudes towards teamwork support the sharing of information and seeking knowledge, and members who value playing a role in the team can create an environment that fosters personal learning through the willingness to share and seek information related to group goals and processes. Therefore, our hypothesis is as follows:

H3: Teamwork orientation is positively related to personal learning.

\section{Moderating effect of perceived value congruence}

We suggest that the relative importance of team orientation depends on how much one has value congruence with other members of a team. Dissimilarity in values may engender implicit or explicit differences in individual approaches regarding different aspects of team work that may translate into reduced social and task exchanges among team members (Graves \& Elsass, 2005). The effects of team orientation are likely to be bolstered if one experiences value congruence with other team members. For example, value congruence, which refers to the similarity or correspondence in personal values among individuals, is asserted to promote a common frame of reference that facilitates a smooth flow of information among members by enhancing accuracy and ease of interpersonal communication (Meglino, Ravlin \& Adkins, 1989). People will show a high willingness to exchange information when they experience a shared understanding with other members as a result of shared mental models (Rentsch \& Klimoski, 2001). In the absence of a common understanding, team members tend to have affective conflict that hinders information exchange (Liang, Wu, Jiang \& Klein, 2012) and diminishes collaborative problem solving (De Dreu, 2006). According to Jehn, Northcraft and Neale (1999), employees show low levels of willingness to share information with co-workers whom they perceive to hold dissimilar values.

Congruity in values is argued to enable people to predict how others will act or behave in different situations (Meglino \& Ravlin, 1998). Interpersonal communication and other 
exchanges may be smoother and more efficient when the behaviour of others is predictable (Meglino, Ravlin \& Adkins, 1991), which may offer greater opportunities for learning in team interactions. Experiences of value congruence have also been reported to increase interpersonal attraction and trust (Edwards \& Cable, 2009). Attraction fostered by value congruence promotes harmony and cooperation between members of an organisation (Nemeth \& Staw, 1989), and a cooperative environment is suggested to be conducive for learning (Williams \& Castro, 2010). Likewise, trust is also likely to promote cooperative behaviour towards common goals (Williams, 2001). Without ample trust, team members may be reluctant to collaborate to provide value-added ideas (Cooper \& Sawaf, 1997) that is likely to inhibit opportunities for effective learning. Based on the above discussion, we suggest the following:

H4: Teamwork orientation - personal learning relationship is stronger when an individual team member's perceived value congruence with other team members is higher.

\section{Research design}

\section{Research strategy}

The study was conducted using a non-experimental crosssectional quantitative design. This took the form of a manually distributed, self-report questionnaire making it possible to study participants at an exact point in time. A non-probability sampling, namely, convenience sampling was utilised. This approach is economical, cost-effective and time-saving.

\section{Research method}

\section{Participants and procedure}

All participants were members of two student project teams that completed two different assignments of 14 weeks each at a Norwegian university. The student teams completing the assignments were teams composed of third-year and second-year bachelor students. Team size ranged from three to five members. These teams faced strict deadlines for the completion of their assignments. This work involved shared responsibility and like other team tasks, cooperation, coordination and communication among team members was important for timely and successful completion of the assignment. The use of student project teams is appropriate to gain an understanding of team working in organisations (Medina \& Medina, 2016), as seeking higher education is seen as a proxy of training for an individual's future career (Powell \& Solga, 2010).

We introduced the participants to the research during their classes a few days after they delivered their assignments, and they were asked to volunteer as participants in our research by filling out the survey questionnaire. The researchers asked the participants to fill out the questionnaire individually and stayed with the respondents while they did this to ascertain the instructions were followed. The sample consists of 120 students (34.2\% male students and $65.8 \%$ female students). Fifty-two per cent of the students sampled were from third year, while $48 \%$ came from second year. Most of the sampled students (84.2\%) were between the age group 18-27 years, with the mean age 24.4 years. Table 1 shows the demographic characteristics of the respondents.

\section{Measures}

\section{Cultural values}

The scale developed by Yoo et al. (2011) was used to measure cultural values. The scale is designed to measure cultural values of UA, PD, collectivism-individualism and masculinity-femininity at the individual level. Five of the survey items address UA, three measure PD, four measure collectivism-individualism and four measure masculinityfemininity. The authors reported coefficient alphas of 0.80 , $0.69,0.80$ and 0.77 for UA, PD, collectivism-individualism and masculinity-femininity, respectively. Participants were asked to rate each statement for its importance in their personal lives by ranking the items on a scale that ranged from 1 , strongly disagree, to 7 , strongly agree.

\section{Teamwork orientation}

Teamwork orientation was measured using a five-item scale developed by Scandura (2015). According to previous reports, this scale possesses adequate psychometric properties. Williams et al. (2006) reported a reliability coefficient of 0.94 for the scale in their study. Sample items from this scale are as follows: 'I feel positive about working in teams'. A 7-point scale ranging from strongly disagree to strongly agree was used for responses.

\section{Personal learning}

To measure personal learning, Alavi's (1994) six-item scale was used. The scale has demonstrated adequate psychometric properties $(\alpha=0.90)$ in previous research (Williams et al., 2006). The sample items include: 'I gained a good understanding of the basic concepts of the material'. A sevenpoint scale ranging from strongly disagrees to strongly agree was used for responses.

\section{Perceived value congruence}

Perceived value congruence was measured using a threeitem subjective fit scale developed by Cable and DeRue

TABLE 1: Demographic characteristics of respondents $(n=120)$.

\begin{tabular}{llcc}
\hline Demographic characteristic & Category & Frequency & $\mathbf{\%}$ \\
\hline Gender & Male & 41 & 34.20 \\
& Female & 79 & 65.80 \\
Age & $18-22$ & 59 & 49.16 \\
& $23-27$ & 42 & 35.00 \\
& $28-32$ & 10 & 8.33 \\
& $33-37$ & 3 & 2.50 \\
& $38-42$ & 3 & 2.50 \\
Course & $\geq 43$ & 3 & 2.50 \\
& Marketing research & 64 & 53.30 \\
Year of study & Business English & 56 & 46.70 \\
\multirow{2}{*}{ Expectation met } & Second year & 58 & 48.30 \\
& Third year & 62 & 51.70 \\
\hline
\end{tabular}


(2002). The authors reported a reliability coefficient of 0.91 for the scale. The measure was adapted to reflect individual member's value congruence with other members of the team. The sample items include: 'The things that I value in life are similar to the things other members of my team values'. The responses were captured on a seven-point scale ranging from strongly disagree to strongly agree. Our operationalisation of perceived value congruence is consistent with previous research (Hoffman, Bynum, Piccolo \& Sutton, 2011). All the question items are listed in Table 2.

\section{Results}

\section{Measures validation and data analysis}

The analysis is based on 31 items (indicators). Psychometric properties of the measures were assessed by first performing an exploratory factor analysis. The Kaiser-Meyer-Olkin (KMO) measure of sampling adequacy was 0.781 and Bartlett's test of Sphericity was significant at the 0.001 level, indicating that the data matrix sufficiently correlated to the factor analysis.
Further analysis was performed by the use of partial least square (PLS) (Wold, 1975) using the software application SmartPLS (Ringle, Wende \& Becker, 2015). Partial least square has the capacity to deal with complex models with a high number of constructs, indicators and relationships (Barclay, Higgins \& Thompson, 1995; Hair, Hult, Ringle \& Sarstedt, 2016). All constructs in this study were operationalised as reflective measures. Thus, we assessed the measurement model with respect to individual item reliability, internal consistency and discriminant validity. Using the rule of thumb of accepting items with loadings of 0.707 or more [although loadings of at least 0.5 are acceptable (Barclays et al., 1995)], three indicator items POD2, POD3 and TEO1 present loadings between 0.5 and 0.707 (see Table 2). Internal consistency was examined using Fornell and Larcker's (1981) composite reliability index. In our model, the composite reliability index for all constructs exceeded the acceptable value of 0.7 (Hair, Black, Babin \& Anderson, 2014), with PD construct presenting the lowest (0.788) and personal learning construct the highest (0.950). In terms of Cronbach's $\alpha$, PD has the minimum value of 0.696 .

TABLE 2: Loadings, composite reliability and average variance extracted.

\begin{tabular}{|c|c|c|c|c|c|c|c|}
\hline Construct & CR & $\alpha$ & AVE & Indicators & M & SD & Loadings \\
\hline \multirow[t]{4}{*}{ Collectivism } & 0.80 & 0.79 & 0.61 & Individuals should stick with their group even through difficulties. COLLECTIVISM2 & 5.06 & 1.48 & $0.767 * * *$ \\
\hline & & & & Group welfare is more important than individual rewards. COLLECTIVISM3 & 4.58 & 1.49 & $0.819 * * *$ \\
\hline & & & & Group success is more important than individual success. COLLECTIVISM4 & 4.39 & 1.52 & $0.840 * * *$ \\
\hline & & & & $\begin{array}{l}\text { Group loyalty should be encouraged even if individual goals suffer. } \\
\text { COLLECTIVISM6 }\end{array}$ & 4.08 & 1.39 & $0.701 * * *$ \\
\hline \multirow[t]{6}{*}{ Personal learning } & 0.95 & 0.93 & 0.75 & I gained a good understanding of the basic concepts related to the course. INL1 & 5.04 & 1.29 & $0.881 * * *$ \\
\hline & & & & I developed an ability to communicate clearly about the subject. INL2 & 4.57 & 1.36 & $0.843 * * *$ \\
\hline & & & & I learned to interrelate the important issues in the course materials. INL3 & 4.64 & 1.25 & $0.862 * * *$ \\
\hline & & & & I learned a great deal of factual material in this course. INL4 & 4.61 & 1.27 & $0.869 * * *$ \\
\hline & & & & I learned to identify the central issues of the course. INL5 & 4.79 & 1.23 & $0.906 * * *$ \\
\hline & & & & I improved my ability to integrate facts from the course material. INL6 & 4.95 & 1.23 & $0.823 * * *$ \\
\hline \multirow[t]{4}{*}{ Masculinity } & 0.88 & 0.82 & 0.65 & It is important for men to have a professional career than it is for women. MAS1 & 1.99 & 1.72 & $0.730 * * *$ \\
\hline & & & & $\begin{array}{l}\text { Men usually solve problems with logical analysis; women usually solve problems } \\
\text { with intuition. MAS2 }\end{array}$ & 2.55 & 1.69 & $0.806 * * *$ \\
\hline & & & & $\begin{array}{l}\text { Solving difficult problems usually requires an active, forcible approach, which is } \\
\text { typical of men. MAS3 }\end{array}$ & 2.41 & 1.61 & $0.881 * * *$ \\
\hline & & & & There are some jobs that a man can always do better than a woman. MAS4 & 3.06 & 2.18 & $0.798 * * *$ \\
\hline \multirow[t]{3}{*}{ Power distance } & 0.79 & 0.69 & 0.56 & $\begin{array}{l}\text { People in higher positions should make most decisions without consulting people } \\
\text { in lower positions. POD1 }\end{array}$ & 3.10 & 1.63 & $0.908 * *$ \\
\hline & & & & $\begin{array}{l}\text { People in higher positions should not ask the opinions of people in lower } \\
\text { positions too frequently. POD2 }\end{array}$ & 2.77 & 1.62 & $0.638^{*}$ \\
\hline & & & & $\begin{array}{l}\text { People in higher positions should avoid social interaction with people in lower } \\
\text { positions. POD3 }\end{array}$ & 1.91 & 1.50 & $0.668^{*}$ \\
\hline \multirow{6}{*}{$\begin{array}{l}\text { Teamwork } \\
\text { orientation }\end{array}$} & 0.92 & 0.89 & 0.65 & The basic idea of the team concept is good. TEO1 & 5.76 & 1.04 & $0.667 * * *$ \\
\hline & & & & Teams are essential for effective student learning. TEO2 & 5.18 & 1.36 & $0.840 * * *$ \\
\hline & & & & I feel positive about working in a team. TEO3 & 5.45 & 1.36 & $0.822 * * *$ \\
\hline & & & & Teams are good for effective group functioning TEO4 & 5.42 & 1.18 & $0.830 * * *$ \\
\hline & & & & Team work is good for students. TEO5 & 5.68 & 1.08 & $0.814 * * *$ \\
\hline & & & & The team concept helps students. TEO6 & 5,55 & 1.22 & $0.844 * * *$ \\
\hline \multirow{5}{*}{$\begin{array}{l}\text { Uncertainty } \\
\text { avoidance }\end{array}$} & 0.88 & 0.84 & 0.61 & It is important to have instructions spelled out in detail. UNA1 & 5.72 & 1.28 & $0.795 * * *$ \\
\hline & & & & It is important to closely follow instructions and procedures. UNA2 & 5.89 & 1.02 & $0.842 * * *$ \\
\hline & & & & Standardised work procedures are helpful. UNA3 & 5.88 & 1.10 & $0.711 * * *$ \\
\hline & & & & $\begin{array}{l}\text { Rules and regulations are important because they inform me of what is expected } \\
\text { of me.UNA4 }\end{array}$ & 6.01 & 1.11 & $0.822 * * *$ \\
\hline & & & & Instructions for carrying out work activities are important. UNA5 & 5.76 & 1.17 & $0.723 * * *$ \\
\hline \multirow[t]{3}{*}{ Value congruence } & 0.93 & 0.89 & 0.82 & My personal values match my team members' values and ideals. VAC1 & 5.55 & 1.44 & $0.898 * * *$ \\
\hline & & & & $\begin{array}{l}\text { The things that I value in life are similar to the things other members in my team } \\
\text { value. VAC2 }\end{array}$ & 5.15 & 1.39 & $0.890 * * *$ \\
\hline & & & & My team members' values provide a good fit with the things I value. VAC3 & 5.34 & 1.36 & $0.930 * * *$ \\
\hline
\end{tabular}

$\mathrm{CR}$, composite reliability; $\alpha$, alpha; AVE, average variance extracted; $M$, mean; $\mathrm{SD}$, standard deviation.

${ }^{*}, p<0.05$ (two-tailed); **, $p<0.01 ; * * *, p<0.001$ 
Discriminant validity indicates the extent to which a given construct is different from other latent constructs. Fornell and Larcker (1981) suggest the use of average variance extracted (AVE) such that a score of 0.5 for the AVE indicates an acceptable level. Average variance extracted by our measures ranges from 0.56 to 0.82 , all above the acceptable value of 0.5 (see Table 2). Further assessment of discriminant validity of the latent variables in the PLS path model was performed using Fornell and Larcker's (1981) criterion, which requires the square root of each latent variable's AVE to be greater than the latent variable's correlation with any other construct in the model. Table 3 shows comparison of the square root of the AVE (diagonal values) with the correlations among the constructs. Each variable meets Fornell and Larcker's (1981) criterion in support of discriminant validity. An examination of loadings and cross-loadings shows that all constructs were more strongly correlated with their own measures than with any other constructs, suggesting good convergent and discriminant validity.

\section{Common method variance}

Harman's (1976) single-factor test was used to assess the potential existence of common method bias. Common method variance is assumed to be present if a single factor emerges from the unrotated factor solution or one factor explains the majority of the variance in the variables (Podsakoff \& Organ, 1986). A one-factor solution accounts for only $19.8 \%$ of the overall variance, which indicates that common method variance is not likely to affect the findings of the study. However, this test has been suggested to suffer from some limitation (Kemery \& Dunlap, 1986); hence, we also adopted the marker variable approach (Lindell \& Whitney, 2001; Malhotra, Kim \& Patil, 2006). A marker variable is a variable, which is theoretically unrelated to at least one other variable in the study. We used the marker variable perceived usefulness to estimate the loadings on every item in the PLS path model and observed each item's loadings on its theoretical construct. We compared the estimated path model relationships with and without the marker. All theorised paths maintain their level of statistical significance. This approach to testing common method variance suggests that method variance biases are not likely to confound the interpretations of the results and findings from this study.

\section{Structural model estimation}

The structural model represents the relationships between constructs or latent variables that were hypothesised in the research model. One of the primary goals of PLS is prediction (Hair et al., 2014). Thus, the goodness of a theoretical model is established by the strength of each structural path and the combined predictiveness $\left(R^{2}\right)$ of its exogenous constructs (Chin, 1998; Henseler, Ringle \& Sinkovics, 2009). Falk and Miller (1992) suggest that the variance explained, or $R^{2}$, for endogenous variables should be greater than 0.1. $R^{2}$ values of $0.67,0.33$ or 0.19 for endogenous latent variables are described as substantial, moderate or weak (Chin, 1998; Henseler et al., 2009). However, our goal in this study is not about prediction but to assess the structural relationship between the constructs and to explore the moderating role of individual-level cultural values of UA, PD and masculinity-femininity on collectivism and team orientation relationships. The variance explained for each endogenous dependent construct in this study is worthy in assessing the model's predictiveness.

Assessment of the path coefficients was done by bootstrap analysis in SmartPLS3 to assess the significance of the path coefficients. Table 4 shows the results of the path analysis, while Figure 2 shows the results of the structural model.

H1 states a positive association between collectivism and teamwork orientation. Results from the analysis of the dataset find support for this ( $\beta=0.21, p<0.05$, two-tailed). $\mathrm{H} 2 \mathrm{a}$ states that collectivism-teamwork orientation relationship will be stronger at higher level of UA values. In other words, the association between collectivism and teamwork orientation will be stronger at a higher level of UA. Our study finds support for $\mathrm{H} 2 \mathrm{a}(\beta=0.13, p<0.10$, onetailed). Figure 3 shows the moderating role of UA. At a higher level of UA (plus one standard deviation above the mean value), higher levels of collectivism lead to higher levels of teamwork orientation. Thus, UA strengthens the association between collectivism and teamwork orientation. However, at lower levels of UA (as shown in Figure 3, minus one standard deviation below the mean value), the effect of collectivism on teamwork orientation attenuates (increasing at a slower pace shown by the near flatness of the slope). $\mathrm{H} 2 \mathrm{~b}$ states that the association between collectivism and teamwork orientation will be stronger at lower levels of PD.

TABLE 3: Discriminant validity coefficients.

\begin{tabular}{|c|c|c|c|c|c|c|c|c|c|c|c|}
\hline & 1 & 2 & 3 & 4 & 5 & 6 & 7 & 8 & 9 & 10 & 11 \\
\hline Collectivism $\times$ masculinity (1) & 1.00 & - & - & - & - & - & - & - & - & - & - \\
\hline Collectivism $\times$ power distance $(2)$ & 0.22 & 1.00 & - & - & - & - & - & - & - & - & - \\
\hline Collectivism $\times$ uncertainty avoidance (3) & -0.20 & -0.05 & 1.00 & - & - & - & - & - & - & - & - \\
\hline Personal learning (4) & 0.14 & -0.16 & 0.01 & 0.86 & - & - & - & - & - & - & - \\
\hline Teamwork orientation $\times$ value congruence $(5)$ & -0.12 & -0.04 & 0.12 & -0.16 & 1.00 & - & - & - & - & - & - \\
\hline Value congruence (6) & -0.01 & 0.16 & 0.10 & 0.01 & 0.04 & 0.91 & - & - & - & - & - \\
\hline Team orientation (8) & -0.02 & -0.11 & 0.16 & 0.40 & -0.13 & 0.32 & 0.29 & 0.81 & - & - & - \\
\hline Masculinity (9) & -0.02 & -0.09 & 0.07 & -0.01 & -0.08 & -0.21 & -0.04 & -0.16 & 0.81 & - & - \\
\hline Power distance (10) & -0.09 & -0.04 & -0.05 & -0.06 & 0.14 & -0.13 & -0.09 & -0.09 & 0.29 & 0.75 & - \\
\hline Uncertainty avoidance (11) & 0.08 & -0.05 & -0.14 & 0.22 & -0.03 & 0.36 & 0.08 & 0.29 & -0.27 & -0.13 & 0.78 \\
\hline
\end{tabular}

Note: Bold numbers on the diagonal show the square root of the AVE. Numbers below the diagonal represent the construct correlations. 
TABLE 4: Path coefficients, effect size and variance.

\begin{tabular}{|c|c|c|c|c|c|}
\hline Criterion & Predictor & $\beta$ & $t$-value $\dagger$ & Effect size & VIF \\
\hline \multirow[t]{8}{*}{ Team orientation } & Value congruence & 0.21 & $2.28 * *$ & 0.047 & 1.270 \\
\hline & Collectivism & 0.21 & $2.39 * *$ & 0.056 & 1.055 \\
\hline & Masculinity & -0.07 & 0.89 & 0.006 & 1.188 \\
\hline & Power distance & 0.00 & 0.00 & 0.036 & 1.120 \\
\hline & Uncertainty avoidance & 0.19 & $2.30 * *$ & 0.036 & 1.280 \\
\hline & Collectivism $\times$ masculinity & 0.03 & 0.28 & 0.001 & 1.112 \\
\hline & Collectivism $\times$ power distance & -0.14 & $1.30^{*}$ & 0.022 & 1.111 \\
\hline & Collectivism $\times$ uncertainty avoidance & 0.13 & $1.40^{*}$ & 0.022 & 1.122 \\
\hline \multirow[t]{3}{*}{ Personal learning } & Value congruence & -0.13 & $1.28^{*}$ & 0.019 & 1.127 \\
\hline & Teamwork orientation & 0.43 & $5.31 * * *$ & 0.201 & 1.144 \\
\hline & Teamwork orientation $\times$ value congruence & -0.10 & 1.14 & 0.012 & 1.025 \\
\hline
\end{tabular}

$\dagger$, Based on 1000 bootstrapping samples.

$\beta$, beta; VIF, variance.

$*, p<0.10$ (one-tailed); **, $p<0.05$ (two-tailed); ***, $p<0.001$

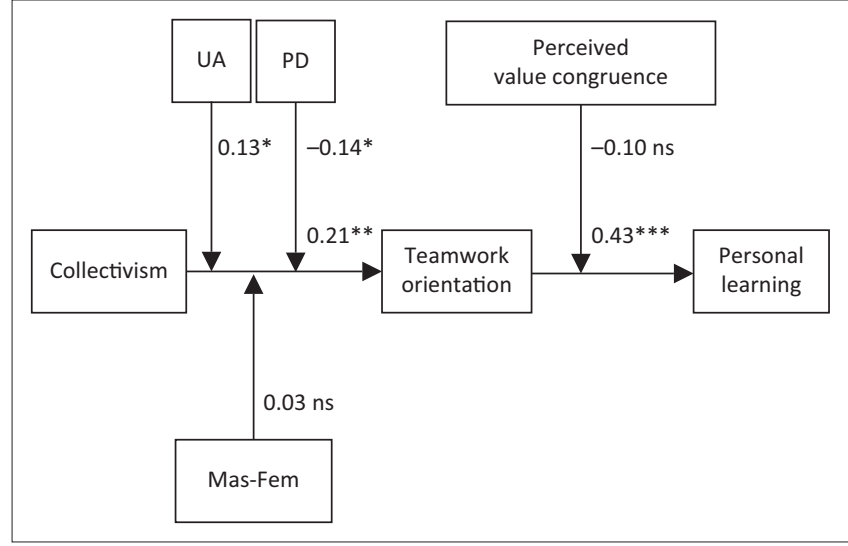

Ns, not significant; UA, uncertainty avoidance; PD, power distance; Mas-Fem, masculinityfemininity.

$*, p<0.10$ (one-tailed); **, $p<0.05$ (two tailed); ***, $p<0.001$ (two-tailed)

FIGURE 2: Results of structural model showing relative strength of the association between constructs.

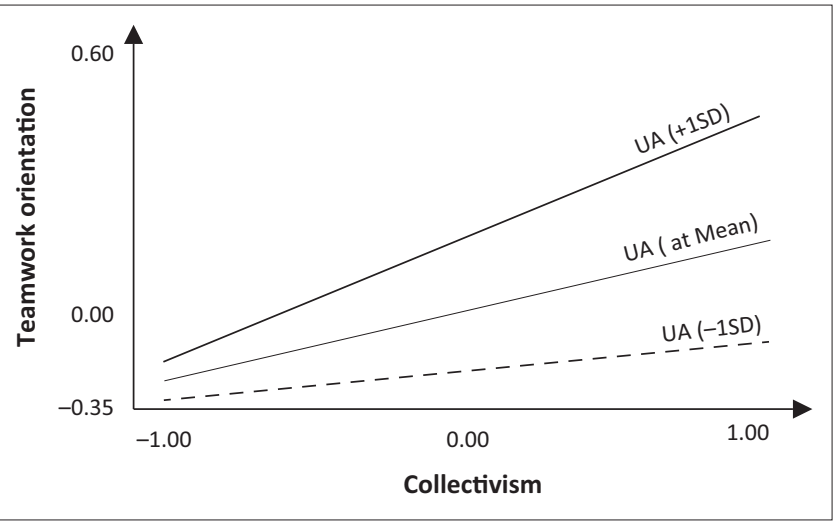

FIGURE 3: Simple slope: Uncertainty avoidance as a moderator between the effect of collectivism on individual team orientation.

Support was found for $\mathrm{H} 2 \mathrm{~b}(\beta=0.14, p<0.10$, one-tailed). Figure 4 shows the moderating role of PD on the association between collectivism and teamwork orientation. At higher levels of PD (plus one standard deviation above the mean), higher levels of collectivism tend to lead to higher levels of teamwork orientation up to a point after which the association between collectivism and teamwork orientation weakens. Thus, at low PD (minus one standard deviation below the mean), collectivism increases teamwork orientation more than at higher levels of PD (plus one standard deviation

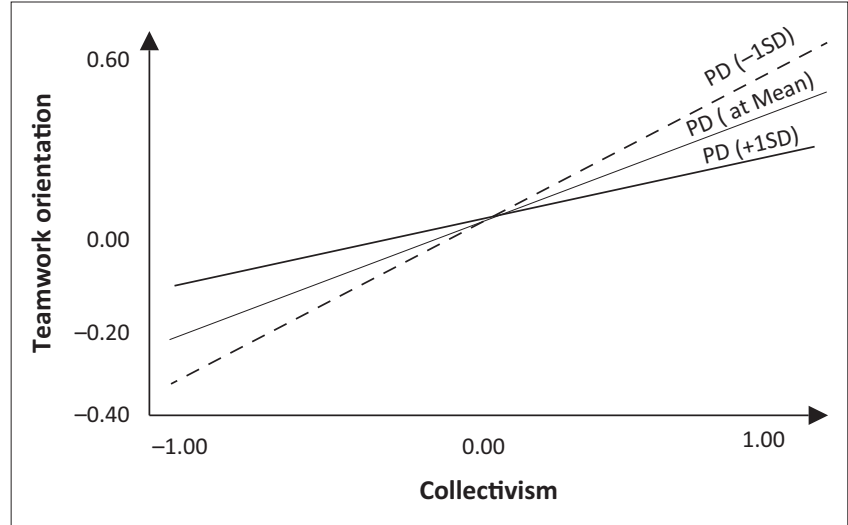

FIGURE 4: Simple slope: Power distance as a moderator between the effect of collectivism on individual team orientation.

above the mean). H2c states that the collectivism-teamwork orientation relationship will be stronger at higher level of femininity (low masculinity), but this was not supported ( $\beta=0.03, p>0.10$, one-tailed). Our study finds support for the positive association between teamwork orientation and personal learning H3 $(\beta=0.43, p<0.001)$. This association between teamwork orientation and personal learning had the highest effect size of 0.21 (see Table 4 ). Thus, according to our study's context, teamwork orientation is the strongest predictor of personal learning in group or team work situations. We did not find support for $\mathrm{H} 4$, rather we found a negative sign for the proposed association showing a possible attenuating effect.

\section{Discussion}

This study examined the role of individual-level cultural values in the occurrence of teamwork orientation and further explored whether there is a significant relationship between teamwork orientation and personal learning and whether perceived value congruence plays a role in this relationship. The study contributes to the existing literature on values, teams and personal learning in the following ways. Building on the previous research that any attitude or behaviour is a product of trade-offs between the values that promote and oppose it (Feldman et al., 2015; Schwartz, 1992) and that values may interact with each other to influence outcomes (Taras et al., 2010), this study provides initial evidence on the 
interactive effects of PD and UA with collectivism in the formation of teamwork orientation. The current understanding on how one's preference for working in teams is shaped is limited with a few studies offering a cognitive basis for the development of such attitudes (Eby \& Dobbins, 1997). We extend the existing literature by providing a values perspective on the occurrence of teamwork orientation. Moreover, the extant research that has examined association between preference to work in teams and personal learning and how this relationship is influenced by personal and contextual factors is extremely scarce. This study contributes to this stream of literature (Williams \& Castro, 2010) by furthering the understanding of the effects of team orientation on personal learning and by incorporating the perceived value congruence as a moderator to evaluate its role in the team orientation - personal learning relationship.

The findings suggest that individual-level differences in values are important in shaping the individual team member's propensity to work interdependently in a team context, while teamwork orientation influences personal learning independent of a team member's perceptions about the degree of congruence between his or her values and those of other team members. Overall, four of the six hypotheses were supported. Collectivist values significantly influenced teamwork orientation, thus supporting the first hypothesis (H1). Support for this finding can be found in previous research that contend that values may influence other dispositional attributes such as attitudes because values are more ingrained and are characterised by general beliefs that transcend specific situations (Bardi \& Schwartz, 2003; England \& Lee, 1974; Gelfand et al., 2007; Lines, 2006). The findings further showed that team members with collectivist values expressed higher levels of team orientation when they endorsed high rather than low UA values, thus providing support for ( $\mathrm{H} 2 \mathrm{a})$. This is consistent with earlier assertions that cultural values may interact with each other in influencing outcomes (McLeay \& Wesson, 2014; Taras et al., 2010). From this, it can be inferred that team members with high UA values construe themselves in a contextualised manner and by virtue of that, they may have a strong tendency to develop an interdependent representation of self that may involve a consciousness of fitting with their environment. Contrarily, individuals low on UA seem to emphasise their own uniqueness, and are more likely to see themselves as independent of others (Mustafa, 2015). Thus, the characteristics of collectivist values to develop an interdependent orientation and directing efforts towards promoting team work and mutual goal attainment may be more congruent with high UA values. This might be the reason that team members who endorsed collectivist values demonstrated high teamwork orientation when they also espoused high rather than low UA values.

We also found support for our prediction in $(\mathrm{H} 2 \mathrm{~b})$ that team members with a collectivist orientation will have a high preference for working in teams when they endorse low PD values rather than high PD values. These findings are again in line with previous contentions that values may act synergistically to bolster or weaken the influence of each other (Kirkman et al., 2006). This provides a clue to construe that an interdependent orientation would be less desirable for individuals who associate importance to hierarchy, and the actions of such team members are less likely to be guided in relation to the preferences and values of other members. On the other hand, members who believe in egalitarian relationships seem to view themselves as not detached from the surrounding social environment and understand their roles as reflective of the feelings and responses of other comembers (Mustafa, 2015). Hence, collectivist values will shape a high teamwork orientation when individual team members consider other members as moral equals and the emphasis is placed on team processes that are built on consultation and open communicative interaction among team members. The findings further revealed that the combined effect of masculinity-femininity and collectivism on teamwork orientation was not significant, implying that we did not find support for $(\mathrm{H} 2 \mathrm{c})$.

In support of our hypothesis (H3), we found that teamwork orientation was positively related to personal learning. This lends credence to the previous evidence that members with a high teamwork orientation are likely to learn more in team settings (Williams \& Castro, 2010). However, the results with respect to the role of value congruence in the teamwork orientation-learning relationship do not support our prediction (H4). We offer three explanations for this. Firstly, it seems that members with high teamwork orientation overcome the issues of value dissimilarity with other members, and mixed motives or competing demands may not attenuate their propensity to play an active role on the team and act in ways that may improve group functioning (Brickson, 2000). Secondly, high similarity in values may be expected to be less favourable for learning, as members with similar perspectives may come up with similar conceptual ideas that may foster an environment where communication tends to be monotonous and the exchange of ideas less beneficial for learning because of members' similar approach to work. Thirdly, according to earlier assertions, the salience of attributes changes over time when people engage in longterm and close interactions, gradually shifting their focus from readily and easily detectable attributes (e.g. demographic similarities) to deeper-level attributes, such as values (Jehn et al., 1999). In this study, team members probably did not focus on value congruence with other team members because their interaction time was too short to discover the value priorities of their co-members and that is why they might have relied more on attributes that could be readily observed than the deeper-level sources (values) of those attributes.

\section{Practical implications}

The present study offers several implications for teachers in higher education and managers in organisations. Our findings suggest that organising group activities and encouraging students to participate in such activities will be beneficial for students' learning and personal development. Teachers can nurture students' inclination to participate in 
teamwork by devising exercises that encourage a mix of task and goal interdependence, by facilitating increased contact among team members and by showing support and recognition for team-based activities. This could improve the propensity of students, especially those with low team orientation, to work in team settings that may subsequently have a positive impact on their learning.

Our findings may also benefit practitioners and managers who are responsible for managing teams and facilitating employee learning and development in business organisations and higher education institutions. As teamwork orientation plays an important role in fostering learning, managers should take measures to foster a high level of teamwork orientation within employees. It is important to help employees develop team orientation, because individuals who develop such attitudes appear to overcome issues of diversity and effectively contribute to the group processes irrespective of congruity in values with other members. Individuals who develop a tendency to work in a team environment will benefit from the diversity within the team members and will utilise different perspectives and learn from one another (Van Der Vegt \& Bunderson, 2005). Thus, a mix of different backgrounds in assembling teams will be beneficial for personal learning and development if members are high on teamwork orientation.

Our findings suggest that psychological-level cultural values reflect important individual differences that, in turn, may exert meaningful effects on individuals' attitudes regardless of their national cultural affiliation. Accordingly, it is important for managers to learn individual-level cultural values to identify employees who will be more or less inclined to work in team-based settings. For example, high levels of collectivism and UA and low levels of PD are likely to result in high level of acceptance to teamwork. Thus, managers may successfully implement team-based activities by selecting individuals whose value profiles correspond to the requirements of the teamwork.

\section{Limitations and suggestions for future research}

There are several limitations in our research. Firstly, we used a sample of students from one university that limits intraand cross-cultural variation in our sample. Therefore, our conclusions may not hold in different settings at national and international level. Future studies can test the generalisability of our findings by including a sample of students spanning a larger number of higher education institutions within and across societies. Researchers who would like to extend our research into occupational settings should include employees associated with workplace teams in different organisations. Secondly, we used a cross-sectional design that limits the capability of our study to draw causal inferences with respect to our proposed relationships. Future research could use longitudinal or experimental designs to test the underlying causality.

Thirdly, personal and contextual variables other than individual cultural values and value congruence may also act as predictors of teamwork orientation and moderators of teamwork effects on learning. Future researchers could examine the influence of other personal and contextual variables as antecedents of teamwork orientation and as moderators of its effects. Next, while we found evidence that teamwork orientation influences personal learning, we neither suggested nor tested any hypotheses concerning mediating mechanisms that may potentially link teamwork orientation and learning. For a better understanding of the teamwork orientation - personal learning link, future research should first conceptually clarify the potential mediating mechanisms and then empirically validate them. Lastly, we measured value congruence using perceptions of similarity in personal values in general terms rather than tapping congruence with respect to a particular set of values. Our operationalisation of value congruence this way may have disguised potentially important findings related to teamwork orientation and its relationship with personal learning. Future studies may tap value congruence by assessing similarity with respect to a set of certain values.

\section{Conclusion}

The results of this study suggest that the effects of individual collectivist values on teamwork orientation tend to be influenced by the differences in other individual-level values such as UA and PD, which lends credence to the understanding that cultural values may operate at the individual level and they interact with each other in predicting certain outcome variables such as attitude towards teamwork. Moreover, this study provides support for the earlier assertions that teamwork orientation fosters personal learning, and further reveals that team-oriented members tend to improve their learning without being influenced by issues of dissimilarity in values with other team members.

\section{Acknowledgements Competing interests}

The authors declare that they have no financial or personal relationships that may have inappropriately influenced them in writing this article.

\section{Authors' contributions}

G.M. and R.G.G. equally contributed to the design of the study, collection and analysis of data and writing of the manuscript, while P.M.R. helped in data collection and proofreading of the manuscript.

\section{References}

Abrami, P.C., \& Bures, E.M. (1996). Computer-supported collaborative learning and distance education. American Journal of Distance Education, 10(2), 37-42. https://doi.org/10.1080/08923649609526920

Alavi, M. (1994). Computer-mediated collaborative learning: An empirical evaluation MIS Quarterly, 18(2), 159-174. https://doi.org/10.2307/249763

Alper, S.W. (1975). Racial differences in job and work environment priorities among newly hired college graduates. Journal of Applied Psychology, 60(1), 132-134. https://doi.org/10.1037/h0076342

Barclay, D., Higgins, C., \& Thompson, R. (1995). The partial least squares (PLS) approach to causal modeling: Personal computer adoption and use as an illustration. Technology Studies, 2(2), 285-309. 
Bardi, A., \& Schwartz, S.H. (2003). Values and behavior: Strength and structure of relations. Personality and Social Psychology Bulletin, 29(10), 1207-1220. https:// relations. Personality and Social Psychol
doi.org/10.1177/0146167203254602

Bell, S.T. (2007). Deep-level composition variables as predictors of team performance A meta-analysis. Journal of Applied Psychology, 92(3), 595-615. https://doi. org/10.1037/0021-9010.92.3.595

Bouncken, R., Brem, A., \& Kraus, S. (2016). Multi-cultural teams as sources for creativity and innovation: The role of cultural diversity on team performance. International Journal of Innovation Management, 20(1), 1-34. https://doi.org/ $10.1142 /$ S1363919616500122

Brickson, S. (2000). The impact of identity orientation on individual and organizational outcomes in demographically diverse settings. Academy of Management Review, 25(1), 82-101.

Cable, D.M., \& DeRue, D.S. (2002). The convergent and discriminant validity of subjective fit perceptions. Journal of Applied Psychology, 87(5), 875-884. https:// doi.org/10.1037/0021-9010.87.5.875

Campion, M.A., Medsker, G.J., \& Higgs, A.C. (1993). Relations between work group characteristics and effectiveness: Implications for designing effective work groups. Personnel Psychology, 46(4), 823-847. https://doi.org/10.1111/j.1744-6570.1993. tb01571.x

Chen, G., \& Bliese, P.D. (2002). The role of different levels of leadership in predicting self-and collective efficacy: Evidence for discontinuity. Journal of Applied Psychology, 87(3), 549-556. https://doi.org/10.1037/0021-9010.87.3.549

Cheng, C.Y., Chua, R.Y., Morris, M.W., \& Lee, L. (2012). Finding the right mix: How the composition of self-managing multicultural teams' cultural value orientation influences performance over time. Journal of Organizational Behavior, 33(3), 389-411. https://doi.org/10.1002/job.1777

Chew, I.K.H., \& Putti, J. (1995). Relationship on work-related values of Singaporean and Japanese managers in Singapore. Human Relations, 48(10), 1149-1170. and Japanese managers in Singapore. Human

Chin, W.W. (1998). The partial least squares approach to structural equation modeling. Modern Methods for Business Research, 295(2), 295-336.

Clugston, M., Howell, J.P., \& Dorfman, P.W. (2000). Does cultural socialization predict multiple bases and foci of commitment? Journal of Management, 26(1), 5-30. https://doi.org/10.1177/014920630002600106

Cooper, R.K., \& Sawaf, A. (1997). Executive EQ: Emotional intelligence in leadership and organizations. New York: Grosset/Putnam.

Costa, P.L., Passos, A.M., \& Bakker, A.B. (2014). Team work engagement: A model of emergence. Journal of Occupational and Organizational Psychology, 87(2), 414436. https://doi.org/10.1111/joop.12057

Cross, S.E., \& Madson, L. (1997). Models of the self: Self-construals and gender Psychological Bulletin, 122(1), 5. https://doi.org/10.1037/0033-2909.122.1.5

De Dreu, C.K. (2006). When too little or too much hurts: Evidence for a curvilinear relationship between task conflict and innovation in teams. Journal of Management, 32(1), 83-107. https://doi.org/10.1177/0149206305277795

Dierdorff, E.C., Bell, S.T., \& Belohlav, J.A. (2011). The power of 'we': Effects of psychological collectivism on team performance over time. Journal of Applied Psychology, 96(2), 247-262. https://doi.org/10.1037/a0020929

Dorfman, P.W., \& Howell, J.P. (1988). Dimensions of national culture and effective leadership patterns: Hofstede revisited. Advances in International Comparative Management, 3(1), 127-150.

Driskell, J.E., \& Salas, E. (1992). Collective behavior and team performance. Human Factors, 34(3), 277-288. https://doi.org/10.1177/001872089203400303

Earley, P.C., \& Gibson, C.B. (1998). Taking stock in our progress on individualismcollectivism: 100 years of solidarity and community. Journal of Management, 24(3), 265-304. https://doi.org/10.1177/014920639802400302

Eby, L.T., \& Dobbins, G.H. (1997). Collectivistic orientation in teams: An individual and group-level analysis. Journal of Organizational Behavior, 18(3), 275-295. https:// doi.org/10.1002/(SICI)1099-1379(199705)18:3\%3C275::AID JOB796\%3E3.0.CO;2-C

Edwards, J.R., \& Cable, D.M. (2009). The value of value congruence. Journal of Applied Psychology, 94(3), 654. https://doi.org/10.1037/a0014891

Elenkov, D.S. (1998). Can American management concepts work in Russia? A cross cultural comparative study. California Management Review, 40(4), 133-156. cultural comparative study. Califormi
https://doi.org/10.2307/41165968

England, G.W., \& Lee, R. (1974). The relationship between managerial values and managerial success in the United States, Japan, India, and Australia. Journal of Applied Psychology, 59(4), 411-419. https://doi.org/10.1037/h0037320

Falk, R.F., \& Miller, N.B. (1992). A primer for soft modeling. Akron, OH: University of Akron Press.

Feldman, G., Chao, M.M., Farh, J.-L., \& Bardi, A. (2015). The motivation and inhibition of breaking the rules: Personal values structures predict unethicality. Journal of Research in Personality, 59, 69-80. https://doi.org/10.1016/j.jrp.2015.09.003

Fischer, R., \& Schwartz, S. (2011). Whence differences in value priorities? Individual, cultural, or artifactual sources. Journal of Cross-Cultural Psychology, 42(7), 11271144. https://doi.org/10.1177/0022022110381429

Fornell, C., \& Larcker, D.F. (1981). Evaluating structural equation models with unobservable variables and measurement error. Journal of Marketing Research, 18(1), 39-50. https://doi.org/10.2307/3151312

Fransen, J., Kirschner, P.A., \& Erkens, G. (2011). Mediating team effectiveness in the context of collaborative learning: The importance of team and task awareness. Computers in Human Behavior, 27(3), 1103-1113. https://doi.org/10.1016/j. chb.2010.05.017
Gelfand, M.J., Erez, M., \& Aycan, Z. (2007). Cross-cultural organizational behavior. Annual Review of Psychology, 58(1), 479-514. https://doi.org/10.1146/annurev. psych.58.110405.085559

Graves, L. M., \& Elsass, P. M. (2005). Sex and sex dissimilarity effects in ongoing teams: Some surprising findings. Human Relations, 58(2), 191-221.

Hackman, J. (1987). The design of work teams. In J.W. Lorsch (Eds.), Handbook of organizational behavior (pp. 315-342). Englewood Cliffs, NJ: Prentice-Hall.

Hair, J., Black, W., Babin, B., \& Anderson, R. (2014). Multivariate data analysis. '(7th edn.). London: Prentice Hall International.

Hair Jr, J.F., Hult, G.T.M., Ringle, C., \& Sarstedt, M. (2016). A primer on partial least squares structural equation modeling (PLS-SEM). Thousand Oaks, CA: Sage.

Harman, H.H. (1976). Modern factor analysis. Chicago, IL: University of Chicago Press.

Henseler, J., Ringle, C.M., \& Sinkovics, R.R. (2009). The use of partial least squares path modeling in international marketing. In R.R. Sinkovics, P.N. Ghauri (Eds.), Advances in international marketing (Vol. 20, pp. 277-320). Bingley, UK: Emerald.

Hoffman, B.J., Bynum, B.H., Piccolo, R.F., \& Sutton, A.W. (2011). Person-organization value congruence: How transformational leaders influence work group effectiveness. Academy of Management Journal, 54(4), 779-796. https://doi. org/10.5465/AMJ.2011.64870139

Hofstede, G. (1980). Culture's consequences: International differences in work-related values (Vol. 5). Beverly Hills, CA: Sage.

Hofstede, G. (2001). Culture's consequences: Comparing values, behaviors, institutions, and organizations across nations. (2nd edn.). Thousand Oaks, CA: Sage.

Jaeger, A.M. (1986). Organization development and national culture: Where's the fit? Academy of Management Review, 11(1), 178-190. https://doi.org/10.2307/ fit? Academ
258339

Jackson, (2001). Cultural values and management ethics: A 10-nation study. Human Relations, 54(10), 1267-1302. https://doi.org/10.1177/a019195

Jackson, C.L., Colquitt, J.A., Wesson, M.J., \& Zapata-Phelan, C.P. (2006). Psychological collectivism: A measurement validation and linkage to group member performance. Journal of Applied Psychology, 91(4), 884-899. https://doi.org/ 10.1037/0021-9010.91.4.884

Javidan, M., Dorfman, P.W., De Luque, M.S., \& House, R.J. (2006). In the eye of the beholder: Cross cultural lessons in leadership from project GLOBE. The Academy of Management Perspectives, 20(1), 67-90. https://doi.org/10.5465/AMP.2006. 19873410

Javidan, M., \& House, R.J. (2001). Cultural acumen for the global manager: Lessons from project GLOBE. Organizational Dynamics, 29(4), 289-305. https://doi. org/10.1016/S0090-2616(01)00034-1

Jehn, K.A., Northcraft, G.B., \& Neale, M.A. (1999). Why differences make a difference: A field study of diversity, conflict and performance in workgroups. Administrative Science Quarterly, 44(4), 741-763. https://doi.org/10.2307/2667054

Kemery, E.R., \& Dunlap, W.P. (1986). Partialling factor scores does not control method variance: A reply to Podsakoff and Todor. Journal of Management, 12(4), 525-530.

Kidwell, R.E., \& Bennett, N. (1993). Employee propensity to withhold effort: A conceptual model to intersect three avenues of research. Academy of Management Review, 18(3), 429-456.

Kirkman, B.L., Chen, G., Farh, J.-L., Chen, Z.X., \& Lowe, K.B. (2009). Individual power distance orientation and follower reactions to transformational leaders: A crosslevel, cross-cultural examination. Academy of Management Journal, 52(4), 744764. https://doi.org/10.5465/AMJ.2009.43669971

Kirkman, B.L., Lowe, K.B., \& Gibson, C.B. (2006). A quarter century of culture's consequences: A review of empirical research incorporating Hofstede's cultural values framework. Journal of International Business Studies, 37(3), 285-320. https://doi.org/10.1057/palgrave.jibs.8400202

Kirkman, B.L., \& Shapiro, D.L. (1997). The impact of cultural values on employee resistance to teams: Toward a model of globalized self-managing work team effectiveness. Academy of Management Review, 22(3), 730-757.

Kram, K.E. (1996). A relational approach to career development. In D.T. Hall (Eds.), The career is dead-Long live the career (pp. 132-157). San Francisco, CA: Jossey-Bass.

Liang, T.-P., Wu, J.C.-H., Jiang, J.J., \& Klein, G. (2012). The impact of value diversity on information system development projects. International Journal of Project Management, 30(6), 731-739. https://doi.org/10.1016/j.ijproman.2011.11.006

Lick, D.W. (2000). Whole-faculty study groups: Facilitating mentoring for school-wide change. Theory into Practice, 39(1), 43-49. https://doi.org/10.1207/s15430421 tip3901_7

Lindell, M.K., \& Whitney, D.J. (2001). Accounting for common method variance in cross-sectional research designs. Journal of Applied Psychology, 86(1), 114-121. https://doi.org/10.1037/0021-9010.86.1.114

Lines, R. (2006). The dual role of values in reactions to organizational change: Sensemaking and sense-giving. In R. Lines, I.G. Stensaker \& A. Langley (Eds.), New perspectives on organizational change and learning (pp. 224-58). Bergen: Fagbokforlaget.

Malhotra, N.K., Kim, S.S., \& Patil, A. (2006). Common method variance in IS research: A comparison of alternative approaches and a reanalysis of past research Management Science, 52(12), 1865-1883. https://doi.org/10.1287/mnsc.1060. 0597

Manz, C.C., \& Sims, H.P. (1993). Business without bosses: How self-managing teams are building high performance companies. New York: Wiley.

Mathieu, J., Maynard, M.T., Rapp, T., \& Gilson, L. (2008). Team effectiveness 19972007: A review of recent advancements and a glimpse into the future. Journal of Management, 34(3), 410-476. https://doi.org/10.1177/0149206308316061 
Mayfield, C.O., Tombaugh, J.R., \& Lee, M. (2016). Psychological collectivism and team effectiveness: Moderating effects of trust and psychological safety. Academy of Effectiveness: Moderating effects of trust and
Edership Journal, 20(1), 78-94. McLeay, F., \& Wesson, D. (2014). Chinese versus UK marketing students' perceptions
of peer feedback and peer assessment. The International Journal of Management Education, 12(2), 142-150. https://doi.org/10.1016/j.ijme.2014.03.005

Medina, M.N., \& Medina, M.N. (2016). Conflict, individual satisfaction with team, and training motivation. Team Performance Management, 22(3/4), 223-239. https:// doi.org/10.1108/TPM-10-2015-0047

Meglino, B.M., \& Ravlin, E.C. (1998). Individual values in organizations: Concepts, controversies, and research. Journal of Management, 24(3), 351-389. https://doi. org/10.1177/014920639802400304

Meglino, B.M., Ravlin, E.C., \& Adkins, C.L. (1989). A work values approach to corporate culture: A field test of the value congruence process and its relationship to individual outcomes. Journal of Applied Psychology, 74(3), 424. https://doi.org/ 10.1037/0021-9010.74.3.424

Meglino, B.M., Ravlin, E.C., \& Adkins, C.L. (1991). Value congruence and satisfaction with a leader: An examination of the role of interaction. Human Relations, 44(5), 481-495. https://doi.org/10.1177/001872679104400504

Minkov, M., \& Hofstede, G. (2012). Is national culture a meaningful concept? Cultural values delineate homogeneous national clusters of in-country
regions. Cross-Cultural Research, 46(2), 133-159. https://doi.org/10.1177/ regions. Cross-Cultural
1069397111427262

Mohammed, S., \& Angell, L.C. (2004). Surface-and deep-level diversity in workgroups: Examining the moderating effects of team orientation and team process on relationship conflict. Journal of Organizational Behavior, 25(8), 1015-1039. https://doi.org/10.1002/job.293

Mustafa, G. (2015). The emergence of leader-society value congruence: A crosscultural perspective. The Journal of Values-Based Leadership, 8(2), 31-53.

Mustafa, G., \& Lines, R. (2014). Influence of leadership on job satisfaction: The moderating effects of follower individual-level masculinity-femininity values. Journal of Leadership Studies, 7(4), 23-39. https://doi.org/10.1002/jls.21307

Nemeth, C.J., \& Staw, B.M. (1989). The tradeoffs of social control and innovation in groups and organizations. In L. Berkowitz (Eds.), Advances in experimental socia psychology (Vol. 22, pp. 175-210). New York: Academic Press.

Patterson, P.G., Cowley, E., \& Prasongsukarn, K. (2006). Service failure recovery: The moderating impact of individual-level cultural value orientation on perceptions of justice. International Journal of Research in Marketing, 23(3), 263-277. https:// doi.org/10.1016/j.ijresmar.2006.02.004

Podsakoff, P.M., \& Organ, D.W. (1986). Self-reports in organizational research Problems and prospects. Journal of Management, 12(4), 531-544. https://doi. org/10.1177/014920638601200408

Powell, J.J., \& Solga, H. (2010). Analyzing the nexus of higher education and vocational training in Europe: A comparative-institutional framework. Studies in Higher training in Europe: A comparative-institutional framework. Studies in
Education, 35(6), 705-721. https://doi.org/10.1080/03075070903295829

Rahman, U.U., Rehman, C.A., Imran, M.K., \& Aslam, U. (in press). Does team orientation matter? Linking work engagement and relational psychological contract with performance. Journal of Management Development. https://doi. contract with performance. Jour
org/10.1108/JMD-10-2016-0204

Ralston, D.A., Egri, C.P., de la Garza Carranza, M.T., Ramburuth, P., Terpstra-Tong, J., Pekerti, A. A., et al. (2009). Ethical preferences for influencing superiors: A 41-society study. Journal of International Business Studies, 40(6), 1022-1045. https://doi.org/10.1057/jibs.2008.109

Ralston, D.A., Egri, C.P., Furrer, O., Kuo, M.-H., Li, Y., Wangenheim, F., et al. (2014). Societal-level versus individual-level predictions of ethical behavior: A 48-society study of collectivism and individualism. Journal of Business Ethics, 122(2), 283306.

Rentsch, J.R., \& Klimoski, R.J. (2001). Why do 'great minds' think alike?: Antecedents of team member schema agreement. Journal of Organizational Behavior, 22(2), 107-120. https://doi.org/10.1002/job.81

Ringle, C.M., Wende, S., \& Becker, J.-M. (2015). SmartPLS 3 Bönningstedt: Smart PLS. Retrieved July 15, 2016, from http://www.smartpls.com

Sagiv, L., \& Schwartz, S.H. (2007). Cultural values in organisations: Insights for Europe European Journal of International Management, 1(3), 176-190. https://doi. org/10.1504/EJIM.2007.014692

Salas, E., Sims, D.E., \& Burke, C.S. (2005). Is there a 'big five' in teamwork? Small Group Research, 36(5), 555-599. https://doi.org/10.1177/1046496405277134

Scandura, T.A. (2015). Essentials of organizational behavior: An evidence-based approach. Los Angeles, CA: Sage.

Schwartz, S.H. (1992). Universals in the content and structure of values: Theoretical advances and empirical tests in 20 countries. In M. Zanna (Eds.), Advances in experimental social psychology (Vol 25, pp.1-65). New York: Academic Press.

Schwartz, S.H. (2007). Universalism values and the inclusiveness of our moral universe. Journal of Cross-Cultural Psychology, 38(6), 711-728. https://doi. org/10.1177/0022022107308992

Schwartz, S.H. (2010). Basic values: How they motivate and inhibit prosocial behavior. In M. Mikulincer \& P. R. Shaver (Eds.), Prosocial motives, emotions, and behavior:
The better angels of our nature (pp. 221-241). Washington, DC: American Psychological Association.

Schwartz, S.H., \& Butenko, T. (2014). Values and behavior: Validating the refined value theory in Russia. European Journal of Social Psychology, 44(7), 799-813. https:// doi.org/10.1002/ejsp.2053

Schwartz, S.H., \& Rubel, T. (2005). Sex differences in value priorities: Cross-cultural and multimethod studies. Journal of Personality and Social Psychology, 89(6), 1010-1028. https://doi.org/10.1037/0022-3514.89.6.1010

Singh, S., Chaudhry, A., Vidyarthi, P.R., \& Posthuma, R.A. (2014). Idiosyncratic deals and employee performance: The role of team orientation and social comparison. Academy of Management Proceedings 2014(1), 14703.

Shamir, B. (1990). Calculations, values, and identities: The sources of collectivistic work motivation. Human Relations, 43(4), 313-332. https://doi.org/10.1177/ 001872679004300402

Sharma, P. (2010). Measuring personal cultural orientations: Scale development and validation. Journal of the Academy of Marketing Science, 38(6), 787-806. https:// doi.org/10.1007/s11747-009-0184-7

Slocum, J.W., \& Strawser, R.H. (1972). Racial differences in job attitudes. Journal of Applied Psychology, 56(1), 28-32. https://doi.org/10.1037/h0032136

Smith, P.B., Peterson, M.F., \& Schwartz, S.H. (2002). Cultural values, sources of guidance, and their relevance to managerial behavior: A 47-nation study. Journal of Cross-Cultural Psychology, 33(2), 188-208. https://doi.org/10.1177/0022 022102033002005

Taras, V., Kirkman, B.L., \& Steel, P. (2010). Examining the impact of culture's consequences: A three-decade, multi-level, meta-analytic review of Hofstede's cultural value dimensions. Journal of Applied Psychology, 95(3), 405-439. https:// doi.org/10.1037/a0018938

Triandis, (1995). Individualism \& collectivism. Boulder, CO: Westview Press.

Triandis, (2006). Cultural aspects of globalization. Journal of International Management, 12(2), 208-217. https://doi.org/10.1016/j.intman.2006.02.010

Tsui, A.S., Nifadkar, S.S., \& Ou, A.Y. (2007). Cross-national, cross-cultural organizational behavior research: Advances, gaps, and recommendations. Journal of Management, 33(3), 426-478. https://doi.org/10.1177/0149206307300818

Van der Vegt, G.S., \& Bunderson, J.S. (2005). Learning and performance in multiscipling 2005.17407918

Van Hoorn, A. (2015). Individualist-collectivist culture and trust radius: A multilevel approach. Journal of Cross-Cultural Psychology, 46(2), 269-276. https://doi. org/10.1177/0022022114551053

Wagner, J.A. (1995). Studies of individualism-collectivism: Effects on cooperation in groups. Academy of Management Journal, 38(1), 152-173. https://doi.org/ 10.2307/256731

Walumbwa, F.O., Lawler, J.J., \& Avolio, B.J. (2007). Leadership, individual differences, and work-related attitudes: A cross-culture investigation. Applied Psychology, 56(2), 212-230. https://doi.org/10.1111/j.1464-0597.2006.00241.x

Wang, Z., Li, C., Wu, J., \& Liu, L. (2014). The mediating effect of cooperative goals on the relationship between team orientation and team member exchange. Socia Behavior and Personality, 42(4), 685-693. https://doi.org/10.2224/sbp.2014. 42.4.685

Watson, W.E., Johnson, L., \& Merritt, D. (1998). Team orientation, self-orientation, and diversity in task groups: Their connection to team performance over time. Group \& Organization Management, 23(2), 161-188. https://doi.org/10.1177/ 1059601198232005

Williams, E.A. (2001). In whom we trust: Group membership as an affective context for trust development. Academy of Management Review, 26(3), 377-396.

Williams, E.A., \& Castro, S.L. (2010). The effects of teamwork on individual learning and perceptions of team performance: A comparison of face-to-face and online project settings. Team Performance Management, 16(3/4), 124-147. https://doi. project settings. Team Performance
org/10.1108/13527591011053232

Williams, E.A., Duray, R., \& Reddy, V. (2006). Teamwork orientation, group cohesiveness, and student learning: A study of the use of teams in online distance education. Journal of Management Education, 30(4), 592-616. https://doi. org $/ 10.1177 / 1052562905276740$

Wold, H. (1975). Path models with latent variables: The NIPALS approach. In H.M. Blalock, A. Aganbegian, F.M. Borodkin, R. Boudon \& V. Cappecch (Eds.), Quantitative sociology: International perspectives on mathematical and statistical modeling (pp. 307-357). New York: Academic Press.

Yoo, B., \& Donthu, N. (2002). The effects of marketing education and individual cultural values on marketing ethics of students. Journal of Marketing Education 24(2), 92-103. https://doi.org/10.1177/0273475302242002

Yoo, B., Donthu, N., \& Lenartowicz, T. (2011). Measuring Hofstede's five dimensions of cultural values at the individual level: Development and validation of CVSCALE. Journal of International Consumer Marketing, 23(3-4), 193-210.

Zhang, Y., \& Begley, T.M. (2011). Power distance and its moderating impact on empowerment and team participation. The International Journal of Human Resource Management, 22(17), 3601-3617. 